Kalsaas, B. T. and Kristensen, K. H. (2018). "New approach to develop integrated milestones for planning and production control" In: Proc. 26 ${ }^{\text {th }}$ Annual Conference of the International. Group for Lean Construction (IGLC), González, V.A. (ed.), Chennai, India, pp. 869-878. DOI: doi.org/10.24928/2018/0238. Available at: www.iglc.net.

\title{
NEW APPROACH TO DEVELOPING INTEGRATED MILESTONES FOR PLANNING AND PRODUCTION CONTROL
}

\author{
Bo Terje Kalsaas ${ }^{1}$ and Kai Haakon Kristensen ${ }^{2}$
}

\begin{abstract}
This paper examines the issue of bringing improved structure with integrated milestones into the project and production management process to handle progress and strategic coordination in complex AEC-projects. We address the phases between front-end planning and project execution. In terms of theory, we base our project on a concept of strategic milestone planning and we find inspiration in ideas from the practical world.

The design research approach is applied, and our artefact is a proposed method by which to develop a network of pull-based integrated milestones. The proposal is verified by documentation of the application in a construction project.

In this paper, we argue that the described method can be applied as an improvement of milestone planning both in Last Planner and in more traditional project management.

The present study fills a gap in project management literature, which appears to address milestones in a superficial manner; this is partly the case for Last Planner System for production control. Our study contributes to theory and practice regarding development of milestones.
\end{abstract}

\section{KEYWORDS}

Milestones, Front-end, Result-oriented, Integrated, Pull-Network

\section{INTRODUCTION}

Milestones are an important part of project planning and management, whether traditionally oriented or based on the concepts of Lean Construction (LC). Last Planner System ${ }^{\circledR}$ (LPS) for production management (Ballard, 2000) is a key component of LC and is built up of several elements of which the overarching one is the master plan. The master plan is a milestone plan. Whereas there are detailed descriptions of functionality and development method in the other elements of LPS, this is not the case with the master plan. The latter is more a "given", although its functionality is clearly described. Ballard

\footnotetext{
1 Professor, Dr. Ing, Faculty of Engineering and Science, Department of Engineering Sciences, University of Agder, N-4846 Grimstad, Norway; e-mail: bo.t.kalsaas@uia.no

2 Senior Project Manager, Ph.D. Municipality of Bodø, Development and Real Estate Department, email: kai.haakon.kristensen@gmail.com
} 
and Tommele in (2016: 61), for example, list eight functions in LPS, of which the first is «Specifying what tasks should be done when and by whom, from milestones to phases between milestones, to process within phases, to operations within processes, to steps within operations». To our minds, these authors are missing a point in the list concerning development of milestones and their function for overall management and control.

A traditional way to establish milestones for construction is to split the building period into phases, usually with a milestone for the transition between phases. The phases may be installation, groundwork, foundation, framework superstructure, roofing, interior work, outdoor work and handover. Depending on the provisions and type of contract, the assignment may also entail pre-design and detailed design. What characterizes this approach is a breaking down of the project based on WBS logic (Work Breakdown Structure).

An alternative option that we have observed being used in practice is process-oriented milestone planning in an early phase of projects. A salient example we know well and that has been a source of inspiration for this article is the construction of a new art institute, Bergen Academy of Art \& Design (Statsbygg\&KHiB team, 2017). KHiB relied on guidance from Porsche Consulting when they initiated the project budgeted at approximately NOK 1 billion (start-up sitework in 2014 - handover late 2017). We have found no references to any publication pertaining to process-oriented milestone planning from Porsche Consulting, and we conclude that progress in practice has surpassed that of academia.

It is difficult to say with certainty, based on available information, but the method that Suffolk Construction, Boston, applies to handle design processes (Uusitalo, Olivieri, Seppänen, Pikas and Peltokorpi, 2017) resembles process-oriented milestone planning. The authors write that Suffolk, unlike other cases they have studied, apply a milestonedriven pull plan to manage Level of Detail (LoD) (Leite, Akcamete, Akinci, Atasoy \& Kiziltas, 2011) in BiM based on milestone requirements.

What, then, is process-oriented milestone planning, and what is different from a traditional WBS approach? We shall return to the details but will here offer a few examples of what we might call core processes in construction; these include production, detail design, materials procurement and builder decisions. A building period is normally given, meaning that the dates for start-up and handover are known in advance to the contracting builder. Production can be regarded as a client's need for a basis for work and materials and components, that is, a demand or requirement for both design and procurement processes. Furthermore, the procurement process needs a basis for placing orders from the design process, which is often dependent on decisions made by the owner/client. We can break this down even further and enter more processes, but we shall return to this aspect later. The difference from a purely WBS-based milestone plan is that here, we rely on a pull-based network of sequential dependencies on the general level, whereas the traditional method consists more of isolated nodes, even though there is a basic sequential logic here as well, but no network logic.

Ballard and Tommelein's (2016: 66) update on LPS address milestones: "Pull planning involves the identification and definition of the milestone, or key event that the team will be pulling to; e.g., releasing subsequent work activities. Identifying the 
conditions of satisfaction of the milestone is critical to a successful pull plan. To assure that shared understanding, the first step in pull planning is to co-create with the team a description of the milestone from which to pull-what's included and excluded, what work it releases, etc. The completion of one milestone sets the stage for the beginning of another one."

This describes the use of reverse planning to identify milestones. We are in total agreement so far. Our additional point in this paper, is that we argue for the development of a pull-based network of milestones in the early phases of core processes. Based on our own practice, we claim that reverse planning is a powerful tool for collaboration, but perhaps not equally applicable for revealing structure and dependencies between milestones. Our research question, then, is how to identify a method for development of process-oriented milestones in an early stage of project management. We use the term 'integrated' to describe milestones in such a network.

\section{METHOD}

Design science research is applied as the methodical framework in the article since the objective we aim for is creating and not merely describing something (Koskela, 2008; Lukka, 2003; Hevner, 2007; Kuchler \& Vaishnavi, 2011; Rocha, Formoso, Tzortzopouluos, Fazenda, Koskela \& Tezel, 2012). Design science is based on constructivist theory and correlates to learning by making/constructing. The artefact we want to create is an alternative method for creating process-oriented milestones for construction management, which we define as integrated milestones.

The idea for this study came out of a relatively large building project that was inspired by a consultancy (Porsche Consulting) as they developed their process-oriented milestones and initiated the project as a lean project. This project (Statsbygg \& KHiB team, 2017) is the source of the data used to verify our proposal (artefact), namely a method by which to develop process-oriented milestones. Data were collected via observation and interviews with key personnel. In addition, the project team provided several descriptions (op cit.).

As part of the process to illustrate "state of the art" and to find relevant theory, we first reviewed the literature from the lean construction environment. We got seven hits for "milestones" on IGLC.net but none had a focus identical to ours beyond what is mentioned above in the introduction. Following this, we consulted several sources in what we might term 'traditional project management' or classical "PMI-oriented" literature. It is reason to ask whether milestones in the PMI-literature is comparable to milestones in LP. We will argue that the understanding of the idea of milestones is the same, but the usage is, however, very different, confer the pull planning approach in LP vs. push in the critical path method. Following the search for PMI-oriented literature we proceeded to strategic project management, where we found ideas and concepts that we worked further with to develop a proposed method that, as stated above, we verified with data. Finally, we make a short comment on our findings and results from the discussion concerning the applied theory. 


\section{LITERATURE REVIEW}

In the foregoing, we have referred to lean construction literature without identifying any sources that extend beyond what has already been emphasized. Below are the findings under the categories that we term 'classic project management literature' ("PMI-oriented" literature) and thereafter, 'strategic oriented project management literature'.

\section{CLASSICAL PROJECT MANAGEMENT LITERATURE}

We found Kerzner's (2009) often cited systematic approach to planning scheduling and control to be a representative source in the classical project management literature. His approach starts with identifying the project manager as the planning agent. This responsibility is met through the provision of:

- a complete task definition

- definitions of resource requirements

- major timetable milestones

- definitions of end-item quality and reliability requirements, and

- the basis for performance measurement

Concerning Kerzner's list, we intend to focus on literature describing the inception of the planning process where the development of the milestones is embedded in the set of task definitions. Starting with Kerzner's recommendations, effective planning cannot be accomplished unless the following information requirements are met:

- The statement of work (SOW), a narrative description of the work required for the project

- The project specifications, describing the SOW in a more specific level of detail enabling overall estimates of man-hours, equipment and material estimates.

- The milestones schedule (defined by the project manager), and

- The work breakdown structure (WBS)

The two first items are of course necessary for proper planning and will not be discussed further here. Kerzner's guidance on how to develop a milestones schedule is limited in scope to a project start and stop date; furthermore, it contains "other milestones and data items such as reports etc". In stark contrast to the brief description of how to develop a milestones schedule, Kerzner has an extensive explanation on how to develop the work breakdown structure (WBS). Contrary to the idea of this paper, he emphasizes that the development of a WBS is the first major step in the planning process.

\section{STRATEGY-ORIENTED PROJECT MANAGEMENT LITERATURE}

Searching for answers with a broader perspective by using rather obvious search words such as "Milestone planning", one finds a few publications and a few papers that appear to be relevant to this pursuit. The authors of these publications seem to agree and refer to each other about milestone planning and its significance. The books by Andersen, Grude, and Haug (2009) ${ }^{3}$ and Turner $(2012)^{4}$ present a thorough description of a collaborative

${ }^{3}$ First published in 1984 
milestone planning as a requisite for the strategic development of the projects and comes before any form of work breakdown of the project. Turner and Cochrand (1993) argue for milestone planning as the right planning approach (as opposed to activity planning approach) for all types of projects except projects where the goals and methods are well understood. Most projects have deficiencies in either the goal or planning methodology; hence, milestone planning is the right approach to a planning process, according to Andersen (1996), who characterizes activity planning as hazardous in the early stages. He argues (op cit.: 89) that "it is doubtful whether project planners can foresee all the activities at the beginning of the project" and further "the kind of activities that should be undertaken depend on the results, the successes and misfortunes, of earlier activities", which is in accordance with an LPS principle (Ballard, 2000). Andersen's principal argument for a milestone-oriented start of the planning process should focus on the results that the project is intended to achieve. These results and sub-results should be arranged in the most optimal sequence in order to attain the desired project outcome. His final comment is that the most prominent plan in the project should highlight these matters and not be an activity-based plan that takes the focus away from what is to be achieved.

Based on the theory revealed above combined with findings in the KHiB-case, we present our suggested approach to developing integrated milestones and relate it to other planning tasks. Following our suggested approach (artefact), we will address the KHiBproject for verification purposes.

\section{APPROACH TO DEVELOP INTEGRATED MILESTONES}

This study's artefact based on theory and practice is how to conduct a milestone-driven planning process in collaboration with the project's key actors (e.g. the owner, designers, engineers, main contractor, subcontractors). The method is summarized below:

a. Identify all core processes (and dedicate one owner per process)

b. Identify maximum $15-20$ milestones per core process

c. Find the logical sequence for the minor milestones in each core process by pull scheduling

d. Identify the network and logical sequence between the minor milestones in all core processes

e. Establish basic process information (input/activity/output/due date) for each minor milestone where the Output information should satisfy predefined Conditions of Satisfaction (CoS) such as acceptance, confer Table .

How to conduct a milestone-driven planning process is step two in a sequence of methodological actions. The first is to adapt to a general project management model that many large companies and organizations use. Such a model is normally structured with generic stages and gates that are described in relation to input, activity and required output.

${ }^{4}$ First published in 1993 
Subsequent actions, in a more holistic method, will entail initiating planning sessions for the design process (cf. Figure 1) and likewise for implementation of production processes. The need for production sets the premises for deliveries from design and procurement and so on. This implies that the indicated steps must necessarily undergo one or more iterations before the milestone network is in sync with the lead times, etc.

We have conducted a verification of our proposal and present this in the next section.

\section{VERIFICATION: THE PRACTICAL EXAMPLE FROM KHIB}

At the inception of the detailed design phase of the KHiB project, the project management decided to initiate the planning process by using methods presented by Porsche Consulting (PC) (Statsbygg \& KHiB team, 2017). The basis for the milestone planning session was Statsbygg's project management model with associated main milestones (gates). The project management and the design team deconstructed the project into milestones. Via several iterations, they ended up with milestones distributed over the following core processes: 1. Project management responsibilities, 2. Design., 3. Procurement., 4. End users/equipment., 5. Construction., 6. Quality., 7. Economy.

The resulting milestone schedule identifies all significant milestones in each core process, and they were placed in their logical order indicating their necessary sequence across the core processes. All the key points were then described in detail in terms of necessary input, necessary activities, expected output and finally a due date. A responsible actor was assigned for each milestone. In Figure 1, we take the KHiB example one step further and illustrate a network of pull-oriented milestones, which is in accordance with the concept of strategic milestone planning referred to (Andersen, 1996). The example is greatly simplified, because of space constraints here, compared to KHIB's original plan, but it still holds sufficient substance to illustrate the methodology.

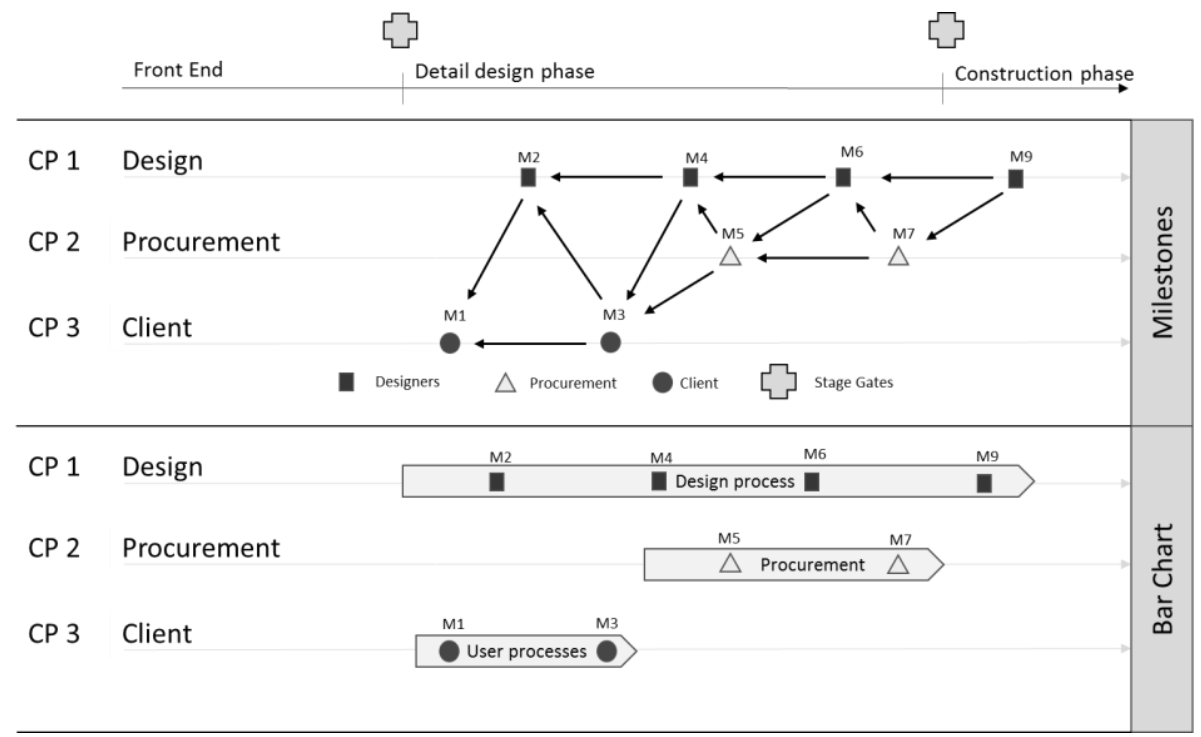

Figure 1: Illustration of a network developed process-oriented milestone plan 
In Figure we have illustrated our outline of the proposed method for milestone planning inspired from Porsche takt ${ }^{5}$ and the experience from KHiB (Statsbygg \& KHiBteam, 2017). To illustrate the concept, the prerequisites for achieving milestone M9 (shop drawings finished) are that M6 (tender material) and then M7 (tender material published) have been completed, cf. the set-up in Table 1 for further details.

We regard the planning process as a societal process in which the significant milestones are identified in brainstorming sessions and by reverse-phase scheduling technique ('planning from the future'). However, some milestones are also push-based within the project context, e.g. finish date in due time before the Christmas sale for shopping malls or before the semester start for schools. Having finished the milestone plan, the slogan in the KHiB-project was "Well, now we have the key to the project. The next task is to identify all procedures necessary to meet each milestone". Hence, the milestone schedule is applied as the basis for more detailed WBS-oriented activity planning and scheduling.

Table 1: Milestones - an example, confer Figure

\begin{tabular}{|l|l|l|l|l|l|}
\hline$\#$ & Milestone & Input & Activity & Output ${ }^{*}$ (CoS) \\
\hline M1 & Floor plans approved & Floor plans, Requirements & Assessment meetings & Approved plans \\
\hline M2 & Freeze Floor Plans & Approval of plans & Finalize Floor Plans & Frozen Floor Plans & [Date] \\
\hline M3 & $\begin{array}{l}\text { Furniture \& Equipment } \\
\text { approved }\end{array}$ & $\begin{array}{l}\text { Approved Floor plans, } \\
\text { Requirements }\end{array}$ & Assessment of products & Approved furniture \& equipment & [Date] \\
\hline M4 & Freeze BIM & All related information & The design process in general & A complete model ready for tendering & [Date] \\
\hline M5 & Tender announced & Approval from client & Announce the coming tender & Tender announced for contractors \\
\hline M6 & Tender material & All previous information & $\begin{array}{l}\text { Finalize design into tender } \\
\text { material }\end{array}$ & All design related material for tender ready & [Date] \\
\hline M7 & $\begin{array}{l}\text { Tender material } \\
\text { published }\end{array}$ & $\begin{array}{l}\text { All design material for } \\
\text { tender }\end{array}$ & $\begin{array}{l}\text { Establish all documents for } \\
\text { tendering }\end{array}$ & Tender material ready for bidding \\
\hline M8 & Contracts established & Contractors bids & Evaluation and selection & Contracts with contractors established \\
\hline M9 & Shop drawings finished & Info from contractors & Producing drawings, Quality work & Complete and approved shop drawings & [Date] \\
\hline
\end{tabular}

The first time the described and illustrated method is applied (Figure and Table ), the experience from KHiB indicates several iterations are needed before the desired quality of sequence and interface logic are achieved. The collaborative effort, however, resulted in a solid foundation for learning and developing detailed design, procurement plans and construction plans. Two important findings in this project occurred immediately after the planning of the milestones. The first was that the project members repeated the same pullbased approach in all further planning as a matter of course. The second was that the deconstruction of the planning activities followed a group-oriented and intuitive segmentation. The various design activities were divided into themes named after the most logical topics and assigned to the actor best suited to take responsibility for each theme. Overall, the themes defined and constituted all activities within the design process (other plans were made for the other core processes).

${ }^{5}$ Porsche Consulting 


\section{REFLECTIONS}

The method we present here expands pull scheduling and the network concept to masterplan level in Last Planner. The pull mechanism itself is not an innovation in this setting; cf. Ballard and Tommelein's (2016) argumentation. What is new is the introduction of the network concept (Andersen, 1996) into milestone planning, and not least, the replacement of pure WBS logic in an early phase with result-oriented planning (deliveries). Of course, in practice planners have always postulated a certain form of network in this context, in that milestones must have a logical sequence; engineering generates input for procurement etc. In the concept we are emphasizing, however, there is a different systemic organization in the approach to network planning for the development of what we have called integrated milestones, and not least in large and relatively complicated projects, we anticipate that it will be able to take project management one step further.

We have used the KHiB project as a source of inspiration and for pending verification of our proposed concept. The milestone plan in the KHiB-project is represented as a large Gantt chart. Even though the project is intended to have a network of milestones, such a network is not explicitly developed. A Gantt chart having a relatively large number of milestones does not visualize structure that emerges in a network diagram. In our opinion, this visualization is important to communicate an understanding to the participants in the project to promote flow, cf. Koskela's (2000) TFV theory. Moreover, we anticipate that an explicit development of milestones in a network based on the LP principle of involvement will yield a better-quality assurance of logical connections and scope than will working in a more linear fashion.

One challenge that must be handled with crystal clarity is to communicate that there must necessarily be a hierarchy of milestones. Most large companies in the field, for example, will have a generic project model as a part of its business plan that lists milestones (gates) at the uppermost level. These kinds of project models are often formulated according to stage-gate logic. Furthermore, when we begin to approach execution, we have to transform milestones into more detailed processes. It is not our intention, however, to discuss this issue any further in the present paper.

The method for developing integrated milestones is generic, but the specific actor(s) who should develop such plans for a specified project will depend on the project delivery model. The KHiB project was a design-bid-build project for which the client's project team developed a milestone plan. This is challenging, in relation to the LP principle of involvement of the executing participants. In such cases, one might perhaps imagine that the client first develops a rough plan, which is then reworked once the executing participants are under contract. Other delivery models with early involvement of contractors provide a better basis for concurrent development of integrated milestones. For example, it may involve different types of collaboration models a team of principal contractor, technical subcontractors and a design team develop a construction project beginning from blueprint level, and not least Integrated Project Delivery (AIA, 2007; Ashcraft, 2012)

Milestones are generally more robust to manage in relation to than are activities, which may change sequence as the building project matures. Although we put most 
emphasis on LPS in this paper, we see nothing that would prevent more traditional project management from being able to benefit from process-oriented milestone planning.

\section{CONCLUSION}

A basic idea in this study is to apply a process approach to creating milestones at the front-end of a construction project, whereas the conventional approach starts up with WBS. The master plan in Last Planner is also based on a conventional approach to milestones, but ideas are present for development in which the pull-concept is included.

Our literature search reveals that the literature in the area of project management is quite deficient and superficial when it comes to development of milestones. However, we find the network approach in a more strategic part of the literature, and we build further on that. Moreover, we intend to think more delivery and less WBS in front-end planning. In addition, we are inspired by the practical world, which in some respects appears to have made more advances than academia in the field concerned.

We place design science research as a basic approach in the present study, and our artefact is our proposal for a new approach to develop integrated milestones for planning and production control. In this paper, we primarily discuss how to conduct a milestonedriven planning process in collaboration with the project's key actors. We place this in a framework that also encompasses an overarching generic project management model with its generic milestones and stage gates, and underlying processes of initiating design and production.

Our proposed method for developing what we define as integrated milestones is verified based on experiences from a relatively large and complicated building project. There is nevertheless a need for further verification and testing. The theory concerning use of pull-oriented network planning as a backdrop for process-oriented milestone planning appears promising.

\section{REFERENCES}

AIA (2007). "Integrated Project Delivery: A Guide." AIA National | AIA California Council.

Ashcraft, H.W. (2012). The IPD Framework. Hanson Bridgett LLP, San Francisco.

Andersen, E.S. (1996). "Warning: activity planning is hazardous to your project's health!"International Journal of Project Management, Vol. 14, No. 2, 89-94.

Andersen, E.S., Grude K.V.\&Haug T. (2009). Goal Directed Project Management. Effective techniques and strategies. London: Kogan Page, ISBN 978749453343.

Ballard, G. (2000). The Last Planner System of Production Control. PhD thesis. Faculty of Engineering. University of Birmingham. Birmingham.

Ballard, G. \&Tommelein, I. (2016). "Current Process Benchmark for the Last Planner System."Lean Construction Journal 2016, (57-89).

Hevner, A. R. (2007). “Three Cycle View of Design Science Research."Scandinavian Journal of Information Systems, 19(2), 87-92.

Kerzner, H. (2009). Project Management; a systems approach to planning, scheduling and controlling. Hoboken, New York, John Wiley \& Sons, Inc. 
Koskela, L. (2000). An Exploration towards a Production Theory and its Application to Construction. VTT Technical Research Centre of Finland.

Koskela, L. (2008). "Which Kind of Science Is Construction Management?" In: Tzortzopoulos, P. \&Kagioglou, M., 16th Annual Conference of the International Group for Lean Construction (p. 51-60), Manchester, UK.

Kuechler, B. \& Vaishnavi, V. (2011). Extending prior research with design science research: two patterns for DSRIS project generation. Service-Oriented Perspectives in Design Science Research, Springer: 166-175.

Leite, F., Akcamete, A., Akinci, B., Atasoy, G. \&Kiziltas, S. (2011). “Analysis modeling effort and impact of different levels of detail in building information models."Automation in Construction, 20(5), 601-609.

Lukka, K. (2003). The constructive research approach. Case study research in logistics. Publications of the Turku School of Economics and Business Administration, Series B, 1(2003), 83-101.

Rocha, C., Formoso, C.T., TzortzopouluosFazenda, P., Koskela, L. \& Tezel, B. (2012). "Design Science research in lean construction: process and outcomes."Workshoppaper, Manchester: University of Salford.

Statsbygg\&KHiB team (2017). LEAN STRATEGY a brief overview. KHiB - booklet no 2, Bergen Academy of Art \& Design. Revised 05/12-2017. Oslo, Norway

Turner. J.R. (2012). The handbook of Project-Based Management. Leading strategic change in organizations.”, McGraw-Hill, London ISBN: 978-0-07-154975-2.

Turner, J.P \&Cochranse, R.A. (1993). "Goals-and-methods matrix: coping with projects with ill defined goals and/or methods of achieving them."International Journal of Project Management, Volume 11, Issue 2, May 1993, 93-102.

Uusitalo, P., Olivieri, H., Seppänen, O., Pikas, E. \&Peltokorpi, A. (2017). Review of Lean Design Management: Processes, Methods and Technologies. In: 25th Annual Conference of the International Group for Lean Construction (p. 571-578), Heraklion, Greece. 